\title{
Photography
}

\section{A Vista of Kahana Bay}

Haryashpal Bhullar, DO

\section{Abstract}

\section{Description}

This is a picture of Kahana Bay in Honolulu, $\mathrm{HI}$ I took when I was visiting my friend stationed at Tripler Army Medical Center last year. Like me, he is a Psychiatry resident and I had not seen him in over a year, so meeting him was quite meaningful to me as we had so much more to talk about. Having this vista behind us while we climbed and shared stories made for one of the best hikes of my life. I often look at this photo and realize the freedom we had to fly to all sorts of beautiful places, see our friends no matter where they were on the globe and how much we took it for granted prior to the COVID-19 pandemic.

Author affiliations are listed at the end of this article.

Correspondence to: Haryashpal Bhullar, DO Orange Park Medical Center 2001 Kingsley Ave Orange Park, FL 32073 (Haryashpal.Bhullar@ hcahealthcare.com)

\section{Keywords}

medicine in the arts; humanities; photography; hiking

\section{Conflicts of Interest}

The author declares he has no conflicts of interest.

Dr. Bhullar is an employee of Orange Park Medical Center, a hospital affiliated with the journal's publisher.

This research was supported (in whole or in part) by HCA Healthcare and/or an HCA Healthcare affiliated entity. The views expressed in this publication represent those of the author(s) and do not necessarily represent the official views of HCA Healthcare or any of its affiliated entities.

\section{Author Affiliation}

1. Orange Park Medical Center, Orange Park, $\mathrm{FL}$ 
HCA Healthcare Journal of Medicine

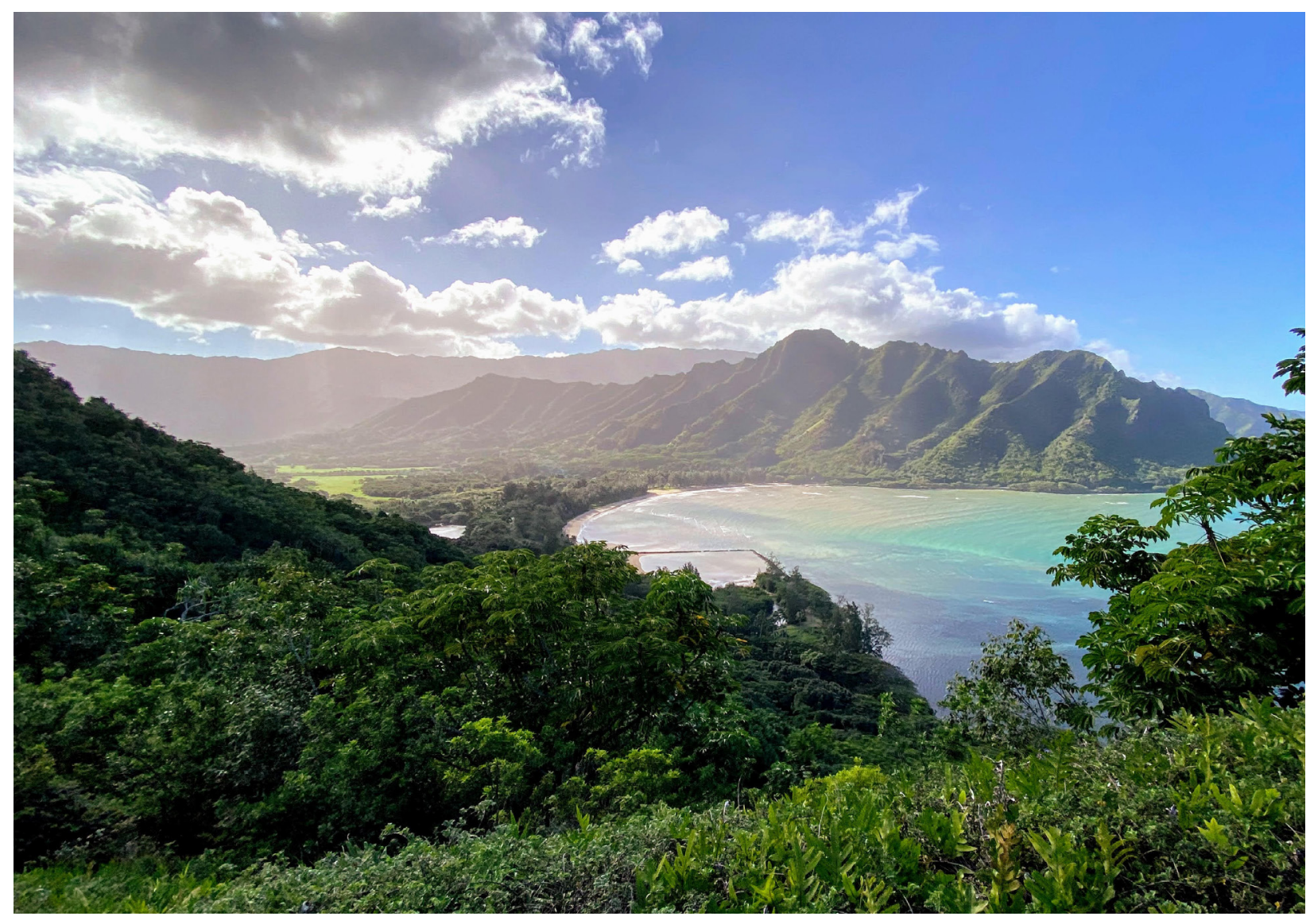

